\section{Caution: interpretation of results of HPLC assay for serum glycated albumin}

\section{Dear Sir}

The exceedingly high values for glycated albumin (normal, $20.2 \pm 1.6 \%$, diabetic, $39.6 \pm 5.4 \%$ ) reported with the high performance liquid chromatographic (HPLC) assay described by Shima et al. [1] are far in excess of values established with any other method, including boronate affinity chromatography (normal range, 1.5$2.6 \%[2]$ ), densitometric scanning of agarose gel electrophoresis (normal range, $0.4-2.0 \%$ [3]), or monoclonal antibody based enzyme linked immunosorbent assay (normal, $2.3 \pm 0.29 \%[4,5]$ ). Careful examination of the principles underlying the HPLC assay and the interpretation of its results are therefore necessary in order to avoid erroneous assignment of the acceptable range of values for non-diabetic populations and for assessment of glycaemic control.

The principal determinants of the extent of nonenzymatic glycation of any protein are the glucose concentration to which it is exposed, the half-life of the involved protein, and the accessibility of free amino groups within the protein for condensation with glucose, the latter in turn dependent on local factors such as $\mathrm{pKa}$ and structural considerations. Thus, not every epsilon amino group of lysine residues becomes glycated; the principal site of albumin glycation in vivo is lysine-525, which has been reported to account for about $33 \%$ of the overall glycation of this protein [6]. Glucose adducts continue to form as a function of time only until equilibrium is reached and, in general, there is a positive relation between protein half-life and extent of in vivo glycation; the dominant factor at low to moderate glucose concentrations appears to be half-life, those proteins with lower half-lives showing greater glycation $[7,8]$.

The number of glucose residues in a molecule of albumin is not the same thing as the percent of total number of albumin molecules that become glycated. In other words, glycation of $20 \%$ of the lysine residues in a single molecule does not mean that $20 \%$ of the total number of albumin molecules are glycated (at one or more sites), and this point is apparently one of confusion in the report by Shima et al. The authors interpret the amount of albumin glycation of $0.37 \mathrm{~mol} / \mathrm{mol}$ protein reported by other investigators [9] as equivalent to glycation of $37 \%$ of the molecules and thereby conclude that other methods, which find considerably lower percentages, underestimate glycated albumin levels. They also interpret their value of $12.5 \mathrm{nmol} / \mathrm{mg}$ of protein as equivalent to glycation of $87 \%$ of the albumin molecules, which is clearly not the case. One $\mathrm{mg}$ of albumin, at a molecular weight of 69,600 , is about $14.4 \mathrm{nmol}$; this means that they found $0.87 \mathrm{~mol}$ of glucose per mol of albumin, and not glycation of $87 \%$ of the total number of albumin molecules.

Since HPLC estimation of glycated albumin uses a boronate column to separate glycated from nonglycated species, it is important to know whether only glycated species bind to boronate. Austin et al. [3] point out that the boronate affinity resin contains nonspecific binding sites which, when very small amounts of protein are applied, lead to an overestimation of the proportion of glycated protein compared with that obtained when larger protein loads are applied. This could be a source of error in the HPLC assay, since only $5 \mu \mathrm{l}$ of sample are injected. Additionally, confirmation is needed that the albumin peak from the first column, which is an ion exchange resin, does not contain other serum proteins; obviously, other glycated proteins contained within the albumin peak that is subsequently applied to the bornoate column would bind to the resin just as would glycated albumin, thus spuriously elevating the values. Evidence confirming that the glycated albumin peak from the second HPLC column does not contain other glycated proteins is lacking.

The finding by Shima et al. of a significant correlation between fructosamine values and glycated albumin levels determined by the HPLC assay is also curious, given that the fructosamine assay is now known to be lacking in methodologic reliability and clinical usefulness [10]. One possible explanation is that there are similar inherent methodologic imperfections regarding specificity and/or susceptibility to interfering substances in the HPLC and the fructosamine assays. Thus, despite good analytical precision (CV of $1-5 \%$ ), the clinical meaning of HPLC glycated albumin results would be subject of the same concerns as those raised for the fructosamine assay which, with an estimated CV of $2-3 \%$, is analytically precise but of questionable clinical usefulness or relevance [10].

Yours sincerely, M.P. Cohen

\section{References}

1. Shima K, Ito N, Hirota M et al. (1988) High performance liquid chromatographic assay of serum glycated albumin. Diabetologia 31: $627-631$

2. Reed P, Bhatnagar D, Dhar H, Winocur PH (1986) Precise measurement of glycated serum albumin by column affinity chromatography and immunoturbidometry. Clin Chim Acta 161: 191199

3. Austin GE, Mullins RH, Morin LG (1987) Non-enzymic glycation of individual plasma proteins in normoglycemic and hyperglycemic patients. Clin Chem 33: 2220-2224

4. Cohen MP, Hud E (1989) Measurement of plasma glycoalbumin levels with a monoclonal antibody based ELISA. J Immunol Meth 122: 279-283

5. Hud E, Cohen MP (1989) Evaluation and performance characteristics of a novel ELISA using a monoclonal antibody to glycated albumin. Clin Chim Acta 185: 157-164

6. Garlick RL, Mazer JS (1983) The principal site of nonenzymatic glycosylation of human serum albumin in vivo. J Biol Chem 258: 6142-6146

7. Nahum HD, Lonchampt M, Duhalt J (1982) Nonenzymatic plasma protein glycosylation: Lack of saturation at high glucose concentration. IRCS Med Sci 10: 436-437

8. Mortensen HB, Volund AA (1984) Variations in hemoglobin $A_{1 c}$ and blood glucose in children with newly diagnosed diabetes mellitus described by a biokinetic model. Diab Metab 10: 18-24

9. Olufemi S, Talwar D, Robb DA (1987) The relative extent of glycation of hemoglobin and albumin. Clin Chim Acta 163:125-136

10. Windeler J, Kobberling J (1990) The fructosamine assay in diagnosis and control of diabetes mellitus; scientific evidence for its clinical usefulnes. J Clin Chem Clin Biochem 28: 129-138

Dr. M.P.Cohen

Institute for Metabolic Research

University City Science Center

3508 Marhet Street, Suite 420

Philadelphia, PA 19104

USA 